\title{
Evaluation of the global impacts of mitigation on persistent, bioaccumulative and toxic pollutants in marine fish
}

Lindsay T Bonito, Amro Hamdoun, Stuart A Sandin

Although persistent, bioaccumulative and toxic pollutants (PBTs) are well-studied, their distribution and variability on a global scale are largely unknown, particularly in marine fish. Using 2,662 measurements collected from peer-reviewed literature spanning 19692012, we examined variability of five classes of PBTs, considering effects of geography, habitat, and trophic level on observed concentrations. While we see large-scale spatial patterning in some PBTs (chlordanes, polychlorinated biphenyls), habitat type and trophic level did not contribute to significant patterning, with the exception of mercury. We further examined patterns of change in PBT concentration as a function of sampling year. All PBTs showed significant declines in concentration levels through time, ranging from $15-30 \%$ reduction per decade across PBT groups. Despite consistent evidence of reductions, variation in pollutant concentration remains high, indicating ongoing risk for exposure to fish with pollutant levels exceeding EPA screening values. The temporal trends indicate that mitigation programs are effective, but that global levels decline slowly. In order for monitoring efforts to provide more targeted assessments of risk to PBT exposure, these data highlight an urgent need for improved replication and standardization of pollutant monitoring protocols for marine finfish. 
1 Evaluation of the global impacts of mitigation on persistent, bioaccumulative and toxic 2 pollutants in marine fish.

3 Lindsay T. Bonito, Amro Hamdoun, Stuart A. Sandin

4

5 Marine Biology Research Department, Scripps Institution of Oceanography, 9500 Gilman Drive, 6 La Jolla, CA 92093-0202, USA

Corresponding author: Stuart A. Sandin, Marine Biology Research Department, Scripps Institution of Oceanography, 9500 Gilman Drive, La Jolla, CA 92093-0202, USA. Email: ssandin@ucsd.edu. Telephone: 001-858-534-4150. Fax: 001-858-534-7313.

\section{Abstract:}

Although persistent, bioaccumulative and toxic pollutants (PBTs) are well-studied individually, their distribution and variability on a global scale are largely unknown, particularly in marine fish. Using 2,662 measurements collected from peer-reviewed literature spanning 1969-2012, we examined variability of five classes of PBTs, considering effects of geography, habitat, and trophic level on observed concentrations. While we see large-scale spatial patterning in some PBTs (chlordanes, polychlorinated biphenyls), habitat type and trophic level did not contribute to significant patterning, with the exception of mercury. We further examined patterns of change in PBT concentration as a function of sampling year. All PBTs showed significant declines in concentration levels through time, ranging from $15-30 \%$ reduction per decade across PBT groups. Despite consistent evidence of reductions, variation in pollutant concentration remains high, indicating ongoing consumer risk of exposure to fish with pollutant levels exceeding EPA screening values. The temporal trends indicate that mitigation programs are effective, but that global levels decline slowly. In order for monitoring efforts to provide more targeted assessments of risk to PBT exposure, these data highlight an urgent need for improved replication and standardization of pollutant monitoring protocols for marine finfish. 
Introduction

Persistent, bioaccumulative, and toxic pollutants (PBTs), namely polychlorinated biphenyls (PCBs), polybrominated diphenyl ethers (PBDEs), organochlorine pesticides (DDTs and CHLs), and mercury $(\mathrm{Hg}, \mathrm{MeHg})$, were widely used throughout the globe in the past century. Although their propensity to bioaccumulate up the food web is well documented, their distribution within seafood across large spatial scales is largely unknown. Nearly 3 billion people rely on fish for their major source of protein (FAO 2014), suggesting that a significant proportion of the world's population is exposed to PBTs through seafood (Asplund et al. 1994; Schade \& Heinzow 1998;

Gobeille et al. 2006; Domingo \& Bocio 2007; Schecter et al. 2010a; Schecter et al. 2010b).

Despite the many potential health benefits from seafood consumption, a risk of pollutant exposure remains.

Assessing the global fate of PBTs is critical for understanding exposure and human health risk to these chemicals. Challenges to such assessments include the costly nature of toxicological sampling and analysis, as well as the high diversity of sources of PBTs that complicates prediction of accumulation patterns, transportability, and persistence. Estimates of global emissions and secondary sources of PBTs are limited to non-existent for certain groups (prior to 2000), limiting the accuracy and availability of global mass budget estimates (Jones \& de Voogt 1999; Breivik et al. 2002a, b, 2007; Lohmann et al. 2007). Furthermore, with insufficient knowledge of biogeochemical cycles and geophysical drivers of pollutant transport, partitioning, and accumulation, a global assessment of human toxin exposure is quite difficult to quantify. To address these limitations, several literature reviews have been conducted to assess the spatial extent of persistent contaminants around the world. Although the quantity of publications is notable, none of these reviews have addressed pollutants screened in food fish on a global 
scale. Rather, reviews conducted thus far have focused on specific pollutant classes in specific regions, most commonly brominated flame retardants in the Arctic (Law et al. 2003; Kallenborn 2006; Yogui \& Sericano 2009; de Wit et al. 2010; Domingo 2012) or pollutants in the Baltic Sea region, where regular monitoring efforts have been in place since the 1980s. There remains a knowledge gap in the spatial trends and variability of contaminant loads at a global scale.

This goal of this review is to address four questions about global pollution: (1) do pollutant concentrations in marine food fish vary between geographic regions, and are these patterns consistent across pollutant groups? (2) does habitat use affect pollutant concentrations? (3) do pollutant levels increase from low to high trophic levels? and (4) have mean pollutant levels changed through time?

First, we elucidate patterns of pollutant concentration at large spatial and temporal scales.

Previous studies have suggested that seafood captured in industrialized regions would have higher concentrations, both in large-scale (thousands of km) (Jensen et al. 1969; Burnett 1971; Brown et al. 1998; Strandberg et al. 1998; Ueno et al. 2005) and small-scale (hundreds of km) (Albaiges et al. 1987; Adams \& McMichael 2007) analyses. However, predicting spatial patterning at global scales is difficult due to the physical properties of PBTs. Most PBTs are human-made chemicals that are semi-volatile, able to be absorbed on the water surface, and become subject to varied global currents and wind patterns. Despite potential global mixing, we may expect regional differences, similar to smaller scale studies. No study has attempted to resolve this question of spatial patterning across ocean basins.

Second, differences in habitat use among species might affect PBT accumulation, as the environment in which a fish spends the majority of its time can affect exposure potential. PBTs 
84

are hydrophobic and strongly adhere to sediments, presumably becoming more available to benthic than to demersal or pelagic species. A few studies have determined that feeding habitat plays a determinant role in the intake and subsequent accumulation of PBTs (Storelli et al. 1998; Storelli \& Marcotrigiano 2000; Borga et al. 2004). Consequently, we expect benthic fish to have higher pollutant concentrations relative to demersal and pelagic taxa due to their increased direct exposure to PBTs.

Third, we test if a central process in ecotoxicology, biomagnification, is maintained when considering aggregated trends in PBT concentrations of numerous fish species at a global scale. Biomagnification is observed commonly, particularly among species in coastal ecosystems close to anthropogenic influence (Bayen et al. 2005). While terrestrial taxa show strong patterns of biomagnification (Kelly et al. 2007), patterns among marine taxa, especially marine fishes, are less clear. Many factors contribute to this heterogeneous landscape, confounded by food web complexity and length (Mizukawa et al. 2009) and the specific species examined (Fisk et al. 2001b). However, when considered across a broad suite of species and geographies, we may expect to see a signal of increasing pollutant levels with increasing trophic level.

Lastly, we assess the effectiveness of global mitigation programs to determine if mean pollutant levels have changed through time. Several national and international agencies are tasked with reducing and eliminating PBTs in the environment, including the United Nation's Stockholm Convention. Although the Convention has the goal of assessing global trends of POPs, at this time only coarse regional analyses are available. Based on global mitigation efforts by major PBT-producing nations, we may expect to observe declines in mean concentration levels, particularly for legacy compounds (mercury and PCBs), over the past 50 years. To be clear, we 
109

110

111

112

113

114

115

116

117

118

119

120

121

122

123

124

125

126

127

128

129

130

131

132

133

will refer to mercury and PCBs as legacy compounds, as their production and use is more longlived and effects better known than modern PBTs, which include organochlorine pesticides and flame retardants (PBDEs). Previous studies have reported successful reductions of PBTs in the environment, particularly in the Arctic and Baltic regions over longer time scales, at least a 10year period (Andersson et al. 1988; Szlinder-Richert et al. 2008; Polak-Juszczak 2009; SzlinderRichert et al. 2009; Riget et al. 2010). At shorter time scales, these temporal trends are harder to distinguish statistically, but suggest decreases (Ikonomou et al. 2011). To the best of our knowledge, no global analysis of temporal trends among marine finfish in mean PBT concentrations has been conducted previously.

Here we provide a synthesis of available published data on muscle tissue of wild-caught, marine fish across the globe for the following contaminants: polychlorinated biphenyls (PCB), polybrominated diphenyl ethers (PBDE), two organochlorine pesticides, dichlorodiphenyltrichloroethane (DDT) and chlordanes ( $\mathrm{CHL})$, and mercury $(\mathrm{Hg}, \mathrm{MeHg})$. The objectives of this study are to synthesize global concentration levels and distribution of PBTs, to investigate the extent of regional, trophic, or habitat-related behavior patterning in data, and evaluate effectiveness of PBT mitigation efforts.

\section{Methods}

\section{Literature Review \& Data Criteria}

We collated data reporting concentrations of PBTs found in marine fish from across the globe.

Two databases were used to identify available literature, Web of Science and Google Scholar, for the time period 1900-2013. Additionally, reference lists of selected papers were used to gather additional sources. Search results were constrained to peer-reviewed journals, grey literature, and government reports. Since we are interested in the effects of fish consumption on 
134 human health, and to standardize results, only studies reporting results from muscle tissue

135 analysis were included. Studies were included only if raw data or mean concentrations of

136 organochlorine pesticides (particularly CHLs and DDTs), polychlorinated biphenyls (PCBs),

137 polybrominated diphenyl ethers (PBDEs), or mercury (total or MeHg) for individual species of

138 marine fish were reported. The following search terms were used to browse the databases: fish*

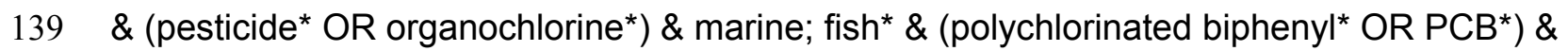

140 marine; fish* \& (polybrominated diphenyl ether* OR PBDE*) \& marine; fish* \& *mercury \&

141 marine. Finally, to be eligible for inclusion, sources had to contain both taxonomic identity, at

142 least to genus level, and capture location; thus, market surveys reporting PBT concentrations of

143 samples from unspecified capture locations were excluded. The results from the primary

144 searches $(n>2500)$ were reviewed, from which 303 papers contained requisite data allowing

145 inclusion in this synthesis (Table S7).

Data Collection

148 Data extracted from the resulting database included pollutant concentration and collection

149 metadata, including capture date, capture location, tissue type, sample size, pollutant

150 congeners, and taxonomic information. We define an individual data record as a mean

151 concentration value calculated per pollutant group, per species, per year, per location for each

152 study (Supplemental S1). For some pollutant groups, the specific congeners reported were not

153 consistent across studies; therefore all congeners per pollutant group were summed to account

154 for the total known exposure potential in an individual fish, or group of fish. The International

155 Council for the Exploration of the Sea (ICES) has selected 7 PCB congeners (CB-28, CB-52,

156 CB-101, CB-118, CB-138, CB-153 and CB-180), dubbed the 'ICES 7', to be used in monitoring

157 of PCBs in foods. These 7 congeners were selected due to their relatively uncomplicated

158 identification and quantification in gas chromatograms and usual contribution to a substantial

159 proportion of the total PCB content in environmental samples (Boalt et al. 2013). 
161 When data were reported graphically, graph digitizing software (Plot Digitizer 2.6.3) was used to

162 extract mean values of pollutants. Additionally, if the sampling date was not reported, collection

163 was estimated to occur 2 years prior to publication date of the paper (sensu Hites 2004).

164

165 All data were converted to $\mathrm{ng} / \mathrm{g}$ wet weight for analyses, using the EPA Exposure Factors

166 Handbook as a guide (EPA 2011). In many instances, concentration values standardized to the

167 fish's lipid concentration were reported. For lipid to wet weight conversions, concentrations

168 were multiplied by species-specific lipid percentages to produce wet weight values. If no lipid

169 percentage was reported, a literature search was conducted to find an estimated value of lipid

170 concentration for each species. For dry weight to wet weight conversions, concentration values

171 were multiplied by species-specific percent moisture values. If moisture values were not

172 indicated, an $80 \%$ moisture value was used as an estimate for all fish species (Murray \& Burt

173 2001). Finally, for contaminant concentration values reported as "below detection limit", a value

174 reflecting $50 \%$ of detection limit was used (EPA 2000). If no detection limit as reported, a zero-

175 value was used.

176

177 In some cases, mean contaminant concentration values were not included in the raw data of

178 publications, only min (a), max (b), median (m) and sample size (n). From these given values,

179 regardless of distribution, mean concentration $(x)$ can be approximated as follows: $\bar{x}=[(a+2 m$

$180+b) / 4]+[(a-2 m+b) / 4 n]($ Hozo et al. 2005).

182 The majority of the reviewed studies did not include morphometric data (body mass or length)

183 for screened specimens. In the cases where collection method was reported, the specimens

184 collected were representative of the associated fishery. Importantly, previous studies have 
185 reported correlations between length or body mass of fish and concentration value (Braune

186 1987; Burreau et al. 2006; Hammerschmidt \& Fitzgerald 2006; Ikemoto et al. 2008). However,

187 for the purpose of this review, body size was not taken into account. As such, this review

188 captures pollutant loads based on available protein source from fish that are typically consumed

189 by humans.

190

191

\section{Global Regions}

Global regions were defined as oceanic basins, accounting for major ocean currents and global wind patterns. Additionally, in order to prevent data overlap between defined global regions, anecdotal fisheries information was also used to delineate regions. Such regional designations offer reasonable boundaries for most species, though there are notable exceptions, e.g. bluefin tuna (Thunnus thynnus), which are capable of trans-oceanic migrations. Fourteen global regions thus were defined (Figure 1); however, due to a paucity of data three regions were excluded from the analysis - the Arctic, the Southern Oceans, and the Red Sea. In order to create adequate sample sizes for statistical analyses, other regions were combined as follows; NE and SE Pacific combined to form the East Pacific region, NW and SW Pacific formed the West Pacific region, and the North Atlantic, South Atlantic, Gulf of Mexico, Baltic Sea, and Caribbean

Sea formed the Atlantic Ocean region. The resulting groups defined for analysis included: East Pacific Ocean (EPO), West Pacific Ocean (WPO), Atlantic Ocean (AO), Mediterranean Sea (MS), and Indian Ocean (IO), which included $>90 \%$ of the data from the original dataset.

\section{Species Classification}

207 To address the effects of habitat and trophic variability on pollutant concentrations, habitat and trophic guild were determined using biological and ecological information obtained from 
210 estimated from biological and ecological descriptions, defining species as pelagic, demersal, or

211 benthic. Species were classified into four trophic guilds, based on trophic level, diet and food

212 items reported in FishBase: herbivore $(\mathrm{H})$, primary predator $(\mathrm{P})$, middle predator $(\mathrm{MP})$, and top

213 predator (TP). In some cases, only genus was reported, in which case the same method applied

214 to generate a genus level trophic or habitat classification. All species names (common and

215 scientific), habitat, and trophic designations can be found in Supplemental Table 7 (S1).

216

217 Human Health Standards

218 Although toxicological health standards have been established by many organizations, for the

219 purposes of this synthesis, only US Environmental Protection Agency (EPA) screening value for

220 target analytes will be evaluated. Following EPA recommendations, the more conservative of

221 the calculated values (noncarcinogenic) will be used because it is more protective of the

222 consumer population. In order to assess human exposure and risk we will use consumption

223 standards developed by the EPA for both recreational fishers and subsistence fishers. These

224 advisory guidelines assume a person to be $70 \mathrm{~kg}$ and have a 70 -year lifespan, consuming and

225 average of 17.5 and 142.4 grams of fish per day for recreational and subsistence fishers,

226 respectively (EPA 2000). EPA defines a screening value as a concentration threshold for target

227 analytes in fish for which exceedance of these should signal more intensive monitoring or

228 evaluation of human health risk.

229

230

Statistical Analyses

231 Data from years 1990-2012 were used for statistical analyses, except for the evaluation of

232 temporal decline of pollutant concentrations where all data were used (1969-2012). The shorter

233 interval better represents modern exposure risk by avoiding potential inflation of concentrations

234 due to variable usage and reporting patterns through time. We tested for differences across all 
235 species to see the effect of region, habitat type, and trophic level on pollutant levels. Change in

236 pollutant levels over time was tested using linear regression. For statistical comparisons of

237 groups, data transformation was not sufficient to apply parametric techniques, primarily due to

238 the unbalanced nature of the design and the lack of homoscedasticity.

239

240 A non-parametric bootstrap approach, analogous to an analysis of variance, was used to

241 evaluate differences between groups (Efron \& Tibshirani 1994). To create a null distribution

242 (similar to F-distribution), samples of pollutant concentrations were drawn randomly with

243 replacement from the total pool of concentration values, constraining group-specific sample

244 sizes to the actual group size in the dataset. The mean squared error, i.e., the sum of the

245 squared differences between group means and the global mean, was bootstrapped 10,000

246 times to create a distribution of mean squared errors. The test statistic, defined as the actual

247 mean squared error of the data, was compared to the bootstrapped null distribution to determine

248 whether the distributions were different among groups (including, but not limited to, the

249 conclusion that the means were different among groups). Graphs are presented with group-

250 specific means and 95\% confidence intervals estimated from group-specific bootstrapping, with

251 replacement. All analyses were performed using the statistical program R version 3.0

252 (http://www.r-project.org).

253

\section{Results}

255 Distribution of Study Sites

256 We collected 2,662 mean concentration values spanning years 1969-2012. Figure 1 details the

257 total number of observations and the relative proportion of pollutants in each global region.

258 There are hotspots of relatively high data density, particularly in regions where monitoring has

259 been established, including the Baltic, northwest Pacific (China), and northeast Pacific (USA \& 
260 Canada). A majority of the studies are from the northern hemisphere and Arctic, with relatively

261 few studies available in the southern hemisphere and less developed nations. Within our

262 dataset, the Atlantic and West Pacific Ocean regions make up 58\% of the total data.

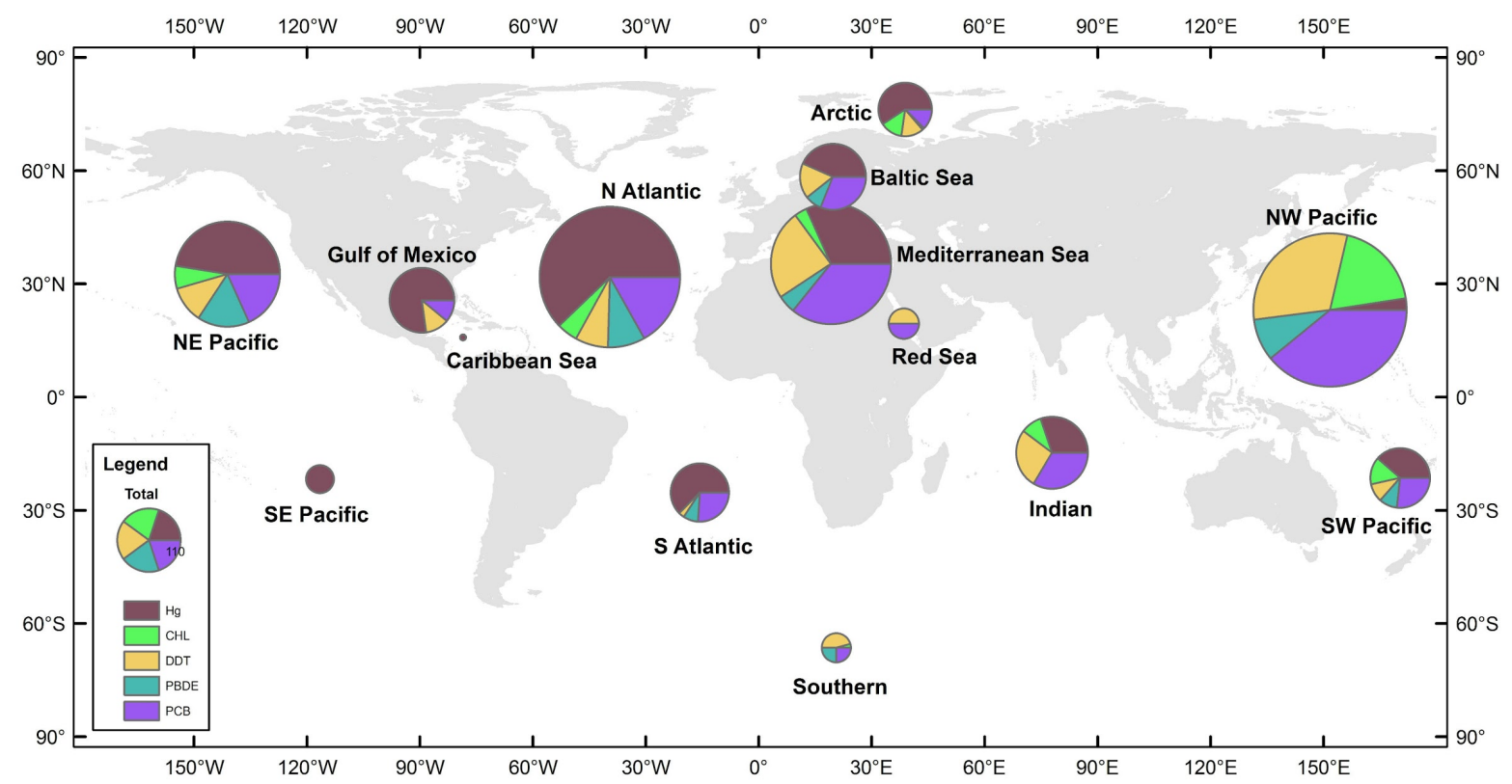

263

264 Despite the wide range of species (842 species) included in this review, sample sizes were

265 largely homogeneous across trophic designations, habitat type and regions through decades

266 (Supplemental Figures 1-2). Detailed information on sample sizes and data distributions are

267 presented in Supplemental Table 1.

268

269

Regional Variability

270 We analyzed the regional variability of mean concentrations across five global regions. The

271 Atlantic Ocean and West Pacific Ocean, compared to other global regions, generally had higher

272 tissue concentrations for all pollutant groups. In contrast, the Mediterranean Sea and the Indian

273 Ocean generally ranked lowest in mean concentration across all five toxins groups (Figure 2).

274 Considering hundreds of species and a multitude of geographic locations, the spread between

275 regional mean concentrations values rarely exceeded an order of magnitude within any one 
276 pollutant group. PCBs showed the highest spread among regional means $(9.3-249.6, \mathrm{ng} / \mathrm{g})$,

277 whereas mercury has the smallest amount of spread among means $(372.7-524.7 \mathrm{ng} / \mathrm{g})$.

278 Minimal differences between regions were found, with the exception of $\mathrm{CHL}(p<0.001 ; n=212)$

279 and PCBs $(p<0.001 ; n=488)$, which have significant differences between regions (Supplemental Table 2).

2

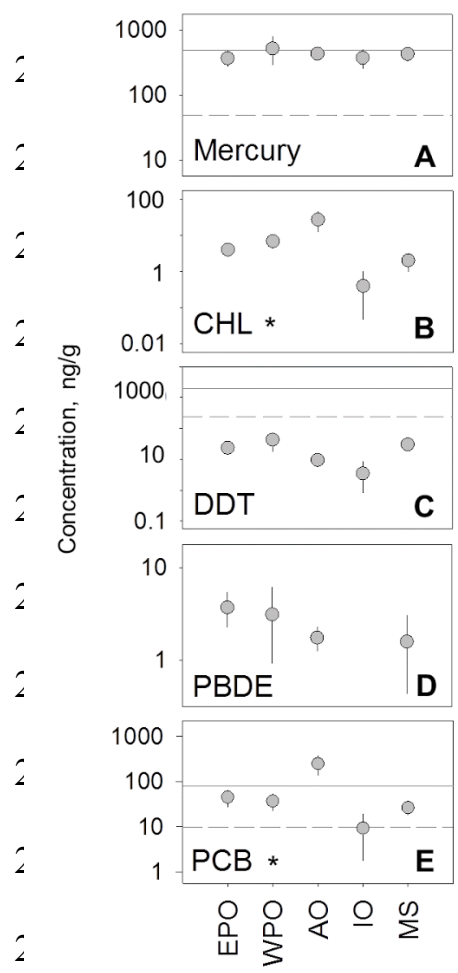
recreational level $(400 \mathrm{ng} / \mathrm{g})$. Similarly, all regional mean concentration values for PCBs were
To investigate underlying drivers of spatial differences, we compared regional mean levels within each trophic guild (Figure 3). Within pollutant groups, we see inconsistent patterns of differences among regional means between trophic levels. For example, within PCBs and CHLs, the Atlantic Ocean has the highest levels of any region across all trophic groups. In spite of this, we failed to document consistent patterns of regional accumulation, even at this smaller scale.

Statistically, no meaningful differences exist between regional means (Supplemental Table 4), with the exception of mercury in herbivorous fish $(p<0.01 ; n=37)$. Although some patterns can be observed, the highly variable means confirm the difficult nature in predicting trends at large spatial scales. 300

\begin{tabular}{|l|l|l|l|l|l|}
\hline Pollutant $^{1}$ & CHL & DDT & Hg & PBDE & PCB
\end{tabular}




\begin{tabular}{|c|c|c|c|c|c|c|c|c|c|c|}
\hline Years & \multicolumn{2}{|c|}{$(1990-2011)$} & \multicolumn{2}{|l|}{$(1990-2012)$} & \multicolumn{2}{|l|}{$(1990-2010)$} & \multicolumn{2}{|c|}{$(1993-2012)$} & \multicolumn{2}{|l|}{$(1990-2012)$} \\
\hline Region ${ }^{2}$ & Mean $[95 \% \mathrm{Cl}]$ & $N$ & Mean [95\% Cl] & $N$ & Mean $[95 \% \mathrm{Cl}]$ & $N$ & Mean $[95 \% \mathrm{Cl}]$ & $N$ & Mean $[95 \% \mathrm{Cl}]$ & $N$ \\
\hline EPO & $4.0[2.7,5.6]$ & 22 & $23.1[17.1,29.6]$ & $\begin{array}{l}27 \\
14\end{array}$ & $372.7[282.6,492.4]$ & 146 & $3.7[2.2,5.4]$ & 53 & $44.9[27.4,65.9]$ & 42 \\
\hline WPO & $6.8[4.3,9.7]$ & 140 & $42.3[18.0,72.7]$ & 5 & $524.7[304.1,810.0]$ & 54 & $3.1[0.9,6.2]$ & 75 & $37.0[22.0,54.5]$ & 218 \\
\hline $\mathrm{AO}$ & $25.9[11.7,44.2]$ & 24 & $9.8[6.2,14.3]$ & 37 & $430.7[380.8,485.1]$ & 482 & $1.7[1.2,2.3]$ & 54 & $249.6[138.8,375.3]$ & 108 \\
\hline 10 & $2.3[0.1,8.2]$ & 14 & $3.7[0.9,8.4]$ & 27 & $434.2[273.6,688.2]$ & 37 & - & - & $9.3[1.8,19.5]$ & 31 \\
\hline MS & $1.8[0.9,2.9]$ & 12 & $29.3[19.5,40.2]$ & 45 & $418.5[307.7,556.3]$ & 76 & $1.6[0.4,3.1]$ & 20 & $26.5[18.4,36.5]$ & 89 \\
\hline \multicolumn{11}{|c|}{ Trophic Level $^{3}$} \\
\hline $\mathrm{H}$ & $7.1[1.9,17.9]$ & 13 & $28.5[7.2,107.2]$ & 15 & $462.9[299.6,680.5]$ & 37 & $2.8[0.6,9.8]$ & 14 & $89.1[20.3,231.0]$ & 41 \\
\hline$P$ & $7.6[3.2,13.8]$ & 42 & $30.5[11.8,66.4]$ & $\begin{array}{l}54 \\
16\end{array}$ & $492.6[346.4,679.6]$ & 65 & $2.5[1.0,5.2]$ & $\begin{array}{l}36 \\
13\end{array}$ & $83.3[33.5,159.5]$ & 99 \\
\hline MP & $8.7[5.2,12.9]$ & 130 & $31.8[16.1,55.5]$ & 4 & $409.2[355.6,469.8]$ & 417 & $2.7[1.6,4.1]$ & 3 & $79.1[44.4,122.8]$ & 265 \\
\hline TP & $7.6[2.7,16.2]$ & 27 & $29.1[11.7,68.7]$ & 47 & $429.7[361.5,509.4]$ & 276 & $3.3[0.9,8.8]$ & 19 & $85.1[29.3,166.5]$ & 83 \\
\hline \multicolumn{11}{|c|}{ Habitat Type } \\
\hline Benthic & $8.1[4.1,12.1]$ & 61 & $31.4[13.2,57.5]$ & $\begin{array}{l}75 \\
14\end{array}$ & $416.1[332.8,489.6]$ & 186 & $2.8[1.2,4.6]$ & $\begin{array}{l}48 \\
12\end{array}$ & $83.1[38.8,130.7]$ & 142 \\
\hline Demersal & $8.2[13.6,3.0]$ & 121 & $31.0[67.9,13.0]$ & 7 & $419.0[515.1,365.9]$ & 365 & $2.9[5.5,1.0]$ & 2 & $80.9[155.3,32.5]$ & 238 \\
\hline Pelagic & $8.3[5.1,16.9]$ & 30 & $28.0[15.2,59.6]$ & 58 & $438.5[358.1,517.5]$ & 245 & $2.5[1.6,5.6]$ & 32 & $79.9[45.7,147.3]$ & 108 \\
\hline
\end{tabular}

1 all data in $\mathrm{ng} / \mathrm{g}$, ww

2 Regions: EPO-East Pacific Ocean; WPO-West Pacific Ocean; AO-Atlantic Ocean; IO-Indian Ocean; MS- Mediterranean Sea.

${ }^{3}$ Trophic Level: H- Herbivores; P- Primary consumer; MP- Middle consumer; TP- Top consumer. 301

302 above the recommended advisory level for subsistence fishers ( $9.83 \mathrm{ng} / \mathrm{g})$, with only the Atlantic

303 also exceeding the level for recreational fishers (80 $\mathrm{ng} / \mathrm{g})$. Contrary to mercury and PCBs, all

304 regions fell below the subsistence fisher health standard (245 ppb) for DDT, and well below the

305 recreational fisher level $(2000 \mathrm{ng} / \mathrm{g})$. In the case of CHLs, all mean regional levels fell well

306 below the screening values for both recreational $(2000 \mathrm{ng} / \mathrm{g})$ and subsistence fishers $(245 \mathrm{ng} / \mathrm{g})$

307 by roughly an order of magnitude. For the remainder of pollutant groups (PBDE and CHL), EPA

308 screening values have yet to be determined.

309

310 Habitat Variability

311 We analyzed habitat type as a predictor of pollutant level, based on data from all capture

312 locations (Figure 4f-j). For nearly all pollutants, differences in fish tissue levels between habitat

313 types were not significant (Supplemental Table 3). Mercury was the only pollutant to have

314 significant differences between mean concentration as a function of habitat type $(p<0.001$; 
$315 \mathrm{n}=795)$. However, mercury behaved contrary to expectations; pelagic habitats $(\bar{x}=438.5,95 \%$

316

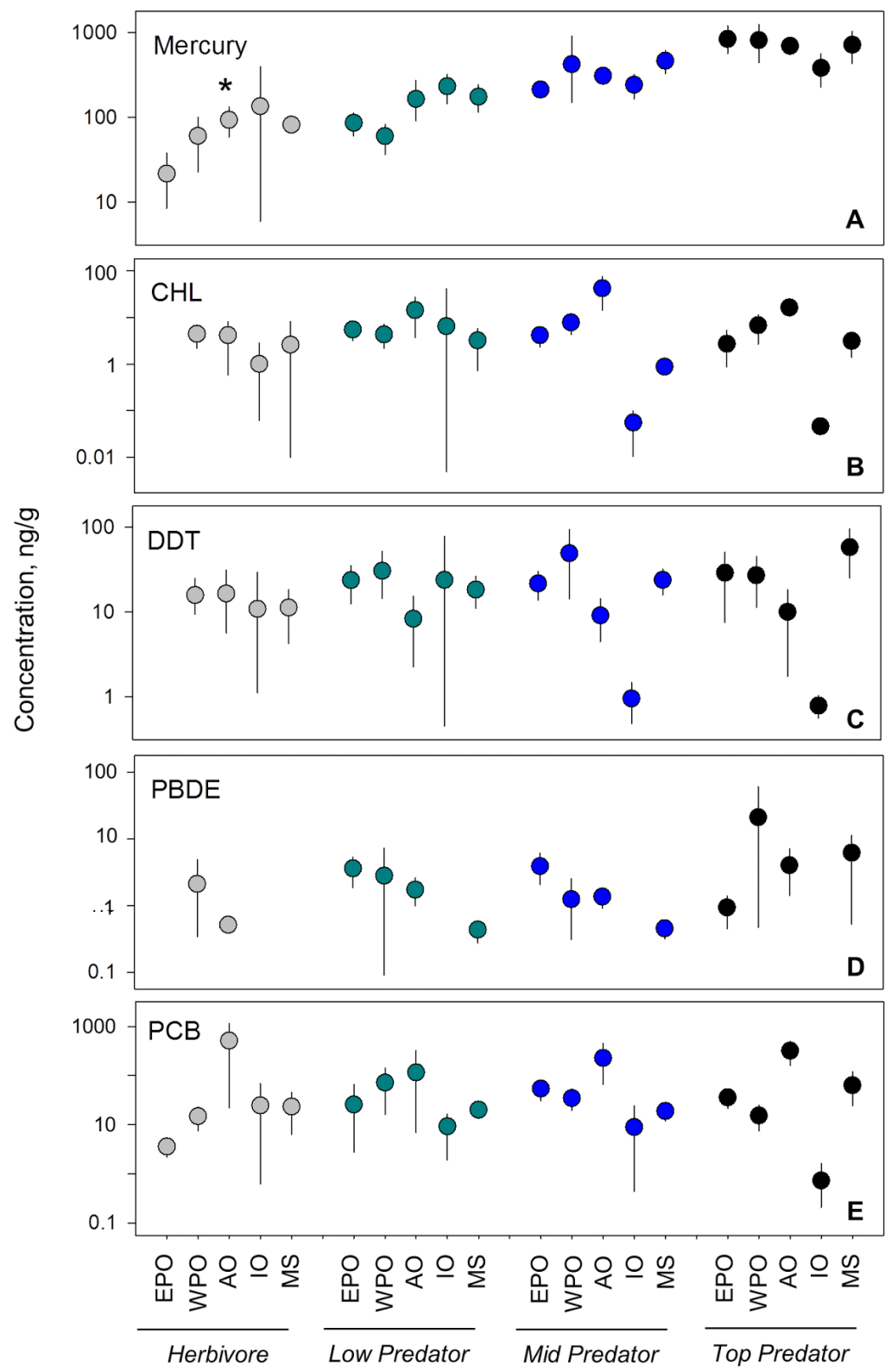

Cl 358.1, 517.5) were most

contaminated and benthic zones $(\bar{x}$ $=416.1,95 \% \mathrm{Cl} 332.8,489.6)$ the

least. The difference between

habitat means within each pollutant

group was extremely low, never

reaching an order of magnitude

difference.

Trophic Variability 
326 We tested for biomagnification effects by comparing mean concentrations across trophic levels

327 for all data combined (Figure 4a-e). We found significant differences in mercury concentrations

328 between trophic levels $(p<0.001 ; n=795)$, with a clear step-wise increase from low to high

329 trophic levels. For the remaining four pollutants, no differences were found between trophic

330 levels (Supplemental Table 3). The inability to detect a signal was likely due to the high

331 variability around the means as the $95 \%$ confidence

332 intervals span up to two orders of magnitude for any

333 given trophic level mean within a pollutant.

334

335 Temporal Trends

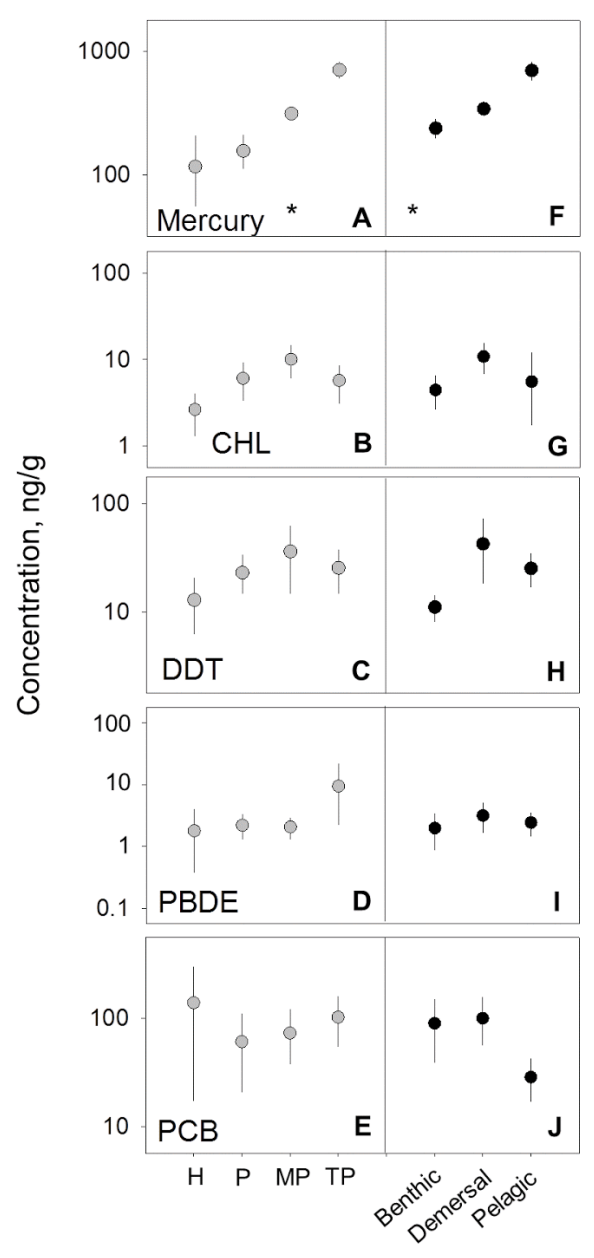


336 Linear regressions were conducted to evaluate the effectiveness of global mitigation efforts to

337 reduce pollutant levels. Temporal trends show reductions in all PBTs from 1969 to 2010 (Figure

338 5). Despite high variability, all linear regressions report a significant negative slope in pollutant

339 concentration over time (Supplemental Table 5). To be sure the reported decline is not a factor

340 a subset of high leverage points (e.g., a small number of anomalously high values in the early

341 sampling years), the regression was tested using a shorter, most recent time frame, 1990-2012.

342 These subsampled data revealed significantly negative trends with similar slopes for all PBTs,

343 with the exception of DDT (Supplemental Table 6). In this shortertime window, there was no

344 evidence of systematic change in DDT concentrations across samples.

345 We subsequently evaluated the regional temporal change of each PBT group (Supplemental

346 Figure 3). Specifically, we investigated whether each region showed a similar pattern of

347 pollutant decline as shown in the global analysis. Regionally, there is a high amount of variability

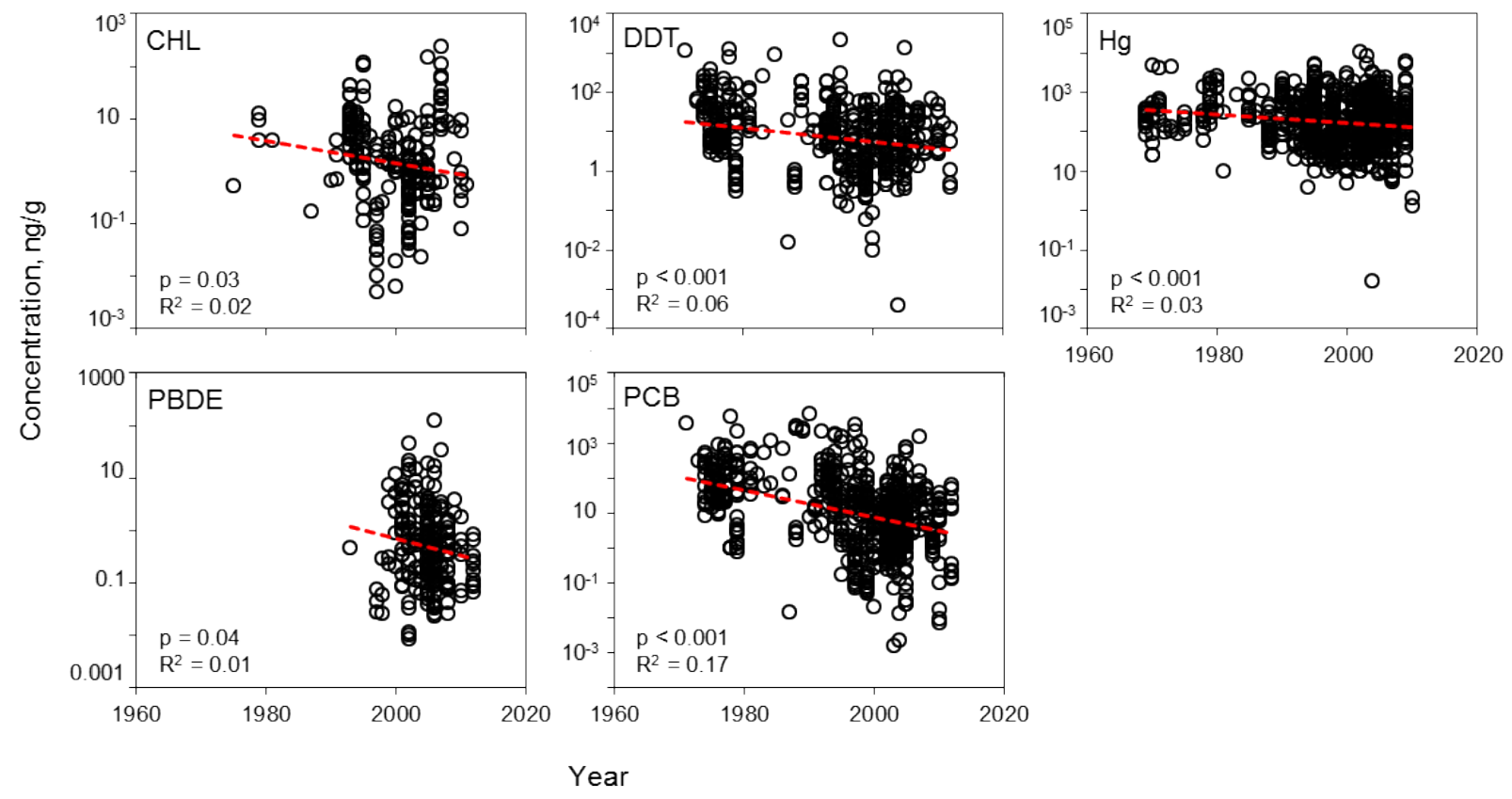

348 in slope values across all PBTs; no one region has a strong signal of increasing or decreasing

349 pollutant levels. Only a few regressions showed a statistically significant decline (see 
350 Supplemental Figure 3). There doesn't seem to be any apparent trend as to which regressions

351 significantly declined, likely due to the limited power and small sample sizes. CHL only reported

352 a decline in the WPO; DDT only in the MS; Hg only in AO; PCB had more significant declines

353 within EPO, WPO, AO, and MS. No significant declines were seen in any regions of PBDEs.

354 However, there are interesting trends within particular PBT groups, specifically in CHL and

355 PBDE. We see that CHLs have a pattern of slightly increasing levels of pollutants in Atlantic and

356 the Mediterranean Sea over the past 20 years. Similarly with PBDEs, half the regions with

357 available data also report increasing levels.

358

359 The number of studies available from each decade can serve as an approximate timeline for the 360 history of global PBT mitigation, particularly the initial awareness of negative health effects of

361 each pollutant. However, a curious lack of data in the 1980s can be seen in all PBTs assessed

362 in this review (Figure 5; Supplemental Figures 1-2). For both PBDEs and PCBs, beginning in

363 the early 2000 s, there is a sharp increase in the volume of data, concurrent with the

364 establishment of the UN's Stockholm Convention and bolstered management and containment

365 efforts across the globe. Although there is a decline in mean concentration value for all

366 pollutants, variability at various time points remains quite high, with $\mathrm{R}^{2}$ values never exceeding

3670.17 . The variability of the mean concentration spans up to three orders of magnitude at any

368 one time point for each PBT.

369

370 Discussion

371 The species included in this analysis encompass a range of characteristics (e.g. distribution,

372 habitat, body size, trophic level, longevity) known to influence pollutant accumulation patterns.

373 Despite such variability, our results show a variety of PBT-specific global differences in

374 concentration across regions, trophic levels, and habitat type. 
Regional Variability

377 Based on previous studies, we expected that regions with more active production or use of

378 PBTs would be linked with higher concentrations in finfish. It is well known that PBTs are

379 capable of long-range transport, but it is unclear how this may affect regional differences at a global scale. As evidenced by many small-scale studies, pollution gradients exist, particularly around point source contamination (Litz et al. 2007; Gewurtz et al. 2011; Greenfield \& Allen 2013). Furthermore, previous literature suggests that a de facto divide exists between the Northern $(\mathrm{NH})$ and Southern Hemispheres $(\mathrm{SH})$, since the $\mathrm{NH}$ encompasses a majority of the industrialized nations and larger human populations, resulting in higher production and emissions of PBTs. With atmospheric exchange between the $\mathrm{NH}$ and $\mathrm{SH}$ being rather slow ( 1yr), we expect minimal transport of PBTs between the two hemispheres.

Our analysis showed regional differences within some PBTs, but not all. For CHLs and PCBs, we see significant differences across space and consistent trends in regional accumulation. Similar regional patterns can be seen in CHLs, DDTs, and PCBs; for example, samples from the Indian Ocean revealed the lowest mean concentration levels within each class. Given the limited data available for PBDEs, likely due to their recent production, we begin to see regional variation but lack the statistical power to confirm. Finally, within mercury although a regional

394 signal is not detected in the trophically aggregated data (Figure 2), within disaggregated data (Figure 3) we see regional variation within the herbivorous guild. Although an analysis across hemispheres (north vs south) could provide further insight to regional pollutant trends, limited data from the southern hemisphere prevents such a detailed analysis. 
399 This study notes the importance of scale in spatial toxicological investigations. The fact that

400 variability exists between regions is not surprising, yet the ability to detect these differences

401 decreases as scale increases. Particularly, as industrial activities are increasingly moving to

402 Asia, elevated PBT emissions are shifting towards China and India (Lohmann et al. 2007). This

403 shift in global emissions and production of PBTs can reduce regional signal, assuming that

404 historical patterns were biased toward North America and Europe. Alternatively, pollutants may

405 mix across water masses, thereby homogenizing environmental concentrations across regions

406 and challenging the accuracy of spatial patterning predictions at a global scale. Regardless of

407 mechanisms (similar introduction across the globe or rapid mixing of heterogeneous input), our

408 data demonstrate that there are minimal regional differences in mean pollutant concentrations in

409 marine finfish.

410

411 The lack of consistent monitoring of marine finfish across habitats and geographies, particularly

412 studies targeting edible muscle tissue, is notable. There is an apparent trend to study estuarine

413 and freshwater species, with few studies centered on pelagic species. This is likely due to the

414 interest in understanding the mechanism behind PBTs bioaccumulation and trophic transfer.

415 Further, due to the lipophilic nature of PBTs, much of the toxicological data available for marine

416 fish is derived from liver tissue, rather than edible muscle tissue. Without a global standardized

417 method of data collection and processing, evaluating the success or failure of mitigation

418 becomes difficult as well as detecting regional differences.

419

420

Ecological and Biological Characteristics

421 In order to provide fish consumption recommendations, many studies have attempted to link 422 species characteristics to pollutant accumulation patterns. The available literature suggests an 423 expectation to see changes in pollutant concentrations based on trophic position and habitat 
424 type. Additionally, numerous studies report strong positive correlations of PBT concentrations 425 and trophic position, particularly when paired with stable isotope analyses (Gobas et al. 1999; 426 Fisk et al. 2001a; Hoekstra et al. 2003). In terms of habitat type, the literature is less clear. A 427 study from the South Adriatic Sea attributed differences in mercury concentrations to feeding 428 habitat, with benthic species showing double the concentration relative to pelagic species 429 (Storelli et al. 1998). However, among the benthic species reported, the range of concentrations 430 was quite high, with concentrations from some benthic species falling below that of pelagics.

431 Our analysis revealed no conclusive evidence that mean pollutant levels were linked

432 systematically to species' trophic level or habitat. Mercury levels revealed the strongest patterns 433 across trophic and habitat types. It is possible that the high level of variability around the means 434 of the other PBTs clouds possible signals of trophic or habitat effects. In short, trophic level or habitat type alone is not a strong enough predictor to guide fish consumption recommendations at the global level for most classes of PBTs.

\section{Pollutant Level Decline}

To date, many published reviews and studies report that concentrations of many classes of PBTs have been decreasing in particular regions for particular species. Such declines are likely due to effective regulation by governmental and environmental protection agencies over the past few decades. However, these reviews are limited in scope, either temporally, spatially, or taxonomically. This synthesis provides a snapshot view of a worldwide decline of five classes of PBTs in marine finfish. The declines are significant, with a mean trend ranging across PBT classes from $10^{0.2}-10^{0.5}$ (or 15-30\%) decline per decade (Figure 5). However, there exist large amounts of variation around these trends with the linear models across time describing $<10 \%$ of the variance within each pollutant class. Even within recent years (2008-2012), we found significant variation in PBT concentrations. Reported concentrations of mercury and PCB span nearly four orders of magnitude when considering only "modern" studies. CHL, DDT and PBDE 
450 have lower variability around the mean compared to mercury and PCBs, but reported

451 concentration still span approximately two orders of magnitude. When looking closer at the

452 regional temporal change of PBT levels, clear trends are harder to distinguish due to reduced

453 statistical power. Of the 24 possible regional analyses, only 7 regions across 4 PBT groups

454 (CHL, DDT, Hg, PCB) reported a statistically significant change through time. PCBs contributed

455 most to the significant declines, as opposed to PBDEs where no region reported a significant

456 decline. This is likely a result of the more recent history of PBDE production and use and limited

457 data prior to 1990 . This high amount of variability can be contributed to a number of factors,

458 including secondary sources of PBTs and environmental processing (Riget et al. 2010).

459 Furthermore, inconsistent sampling techniques and locations can conceal possible trends, even

460 with a region or pollutant. As a consumer, although the mean levels of PBTs tend to be lower

461 now than in 1970, the high variance around this trend suggests that the chance of exposure via

462 a contaminated fish remains non-trivial.

463

464 Conclusion

465 To the best of our knowledge, this is the first study to compile data on wild-caught marine fish

466 with the goal of investigating spatial, life historical, and temporal patterns of tissue

467 concentrations of PBTs at a global scale. Although we expected to see some level of regional

468 distinction of PBTs, we found that regional trends are less distinct and confounded by finer scale

469 details, including trophic level and habitat type. We conclude that the vagaries of global

470 contamination cloud the predictability of toxin accumulation in marine finfish. The lack of

471 standardized monitoring approaches, coupled with the globalization of seafood imports and

472 exports, makes estimating the likely exposure to individual consumers based on market choices

473 challenging. However this analysis reveals the widespread and pervasive nature of persistent,

474 bioaccumulative and toxic chemicals in seafood and the need to tackle these challenges. 
476 In terms of human health, standards are developed in a singular fashion, evaluating risks for

477 only one pollutant at a time. In reality, fish often contain multiple classes of PBTs

478 simultaneously. Understanding additive effects of multiple exposures to PBTs is the next step in

479 determining the "real" exposure risk to consumers, in all kinds of food. The quantification of

480 these potentially synergistic (or antagonistic) effects could dramatically alter the health

481 standards currently used. Furthermore, conclusive health standards still need to be determined

482 for many of the PBTs, including many emerging containments not referenced in this review.

483

484 Based on the results of this synthesis, global efforts to reduce and eliminate PBTs appear to 485 have been fairly successful, given the observed decline in the mean concentration values for 486 PBTs over the past 50 years. However, the variability around this mean remains high, suggesting that the chance for exposure to a "contaminated" fish remains. Continued monitoring, stringent enforcement, and updated policies will be key to ultimately reducing the exposure to humans (and wildlife) to these human-made toxins. Additionally, novel policy and research must continue to address the potential negative effects of emerging contaminants entering our terrestrial and marine environments.

\section{Acknowledgements}

The authors would like to thank several anonymous reviewers for constructive criticisms of the manuscript. We would also like to thank S. Nicklisch, C. Edwards and Y. Eynaud for comments on earlier drafts of the manuscript. 
502

503

504

505

506

507

508

509

510

511

512

513

514

515

516

517

518

519

520

521

522

523

524

525

526

527

528

529

530

531

532

533

534

535

536

537

538

539

540

541

542

543

544

545

546

547

\section{References}

1.

Adams, D.H. \& McMichael, R.H. (2007). Mercury in king mackerel, Scomberomorus cavalla, and Spanish mackerel, S. maculatus, from waters of the south-eastern USA: regional and historical trends. Mar Freshwater Res, 58, 187-193.

2.

Albaiges, J., Farran, A., Soler, M., Gallifa, A. \& Martin, P. (1987). Accumulation and distribution of biogenic and pollutant hydrocarbons, PCBs and DDT in Tissues of western Mediterranean fishes. Marine Environmental Research, 22, 1-18.

3.

Andersson, O., Linder, C.E., Olsson, M., Reutergardh, L., Uvemo, U.B. \& Wideqvist, U. (1988). Spatial differences and temporal trends of organochlorine compounds in biota from the northwestern hemisphere. Archives of Environmental Contamination and Toxicology, 17, 755-765.

4.

Asplund, L., Svensson, B.G., Nilsson, A., Eriksson, U., Jansson, B., Jensen, S. et al. (1994). Polychlorinatedbiphenyls, 1,1,1-trichloro-2,2-bis(p-chlorophenyl) ethane (p,p'-DDT) and 1,1-dichloro-2,2-bis(pchlorophenyl)-ethylene ( $\left.p, p^{\prime}-\mathrm{DDE}\right)$ in human plasma related to fish consumption. Arch Environ Health, 49, 477-486.

5.

Bayen, S., Wurl, O., Karuppiah, S., Sivasothi, N., Lee, H.K. \& Obbard, J.P. (2005). Persistent organic pollutants in mangrove food webs in Singapore. Chemosphere, 61, 303-313.

6.

Boalt, E., Nyberg, E., Bignert, A., Hedman, J. \& Danielson, S. (2013). Polychlorinated biphenyls (PCB) and dioxins and furans. In: HELCOM Core Indicator Report. HELCOM Online.

7.

Borga, K., Fisk, A.T., Hoekstra, P.F. \& Muir, D.C.G. (2004). Biological and chemical factors of importance in the bioaccumulation and trophic transfer of persistent organochlorine contaminants in arctic marine food webs. Environ Toxicol Chem, 23, 2367-2385.

8.

Braune, B.M. (1987). Mercury accumulation in relation to size and age of Atlantic herring (Clupea harengus harengus) from the southwestern Bay of Fundy, Canada. Archives of Environmental Contamination and Toxicology, 16, 311-320.

9.

Breivik, K., Sweetman, A., Pacyna, J.M. \& Jones, K.C. (2002a). Towards a global historical emission inventory for selected PCB congeners - a mass balance approach 1. Global production and consumption. Sci Total Environ, 290, 181-198.

10.

Breivik, K., Sweetman, A., Pacyna, J.M. \& Jones, K.C. (2002b). Towards a global historical emission inventory for selected PCB congeners - a mass balance approach 2. Emissions. Sci Total Environ, 290, 199-224.

11.

Breivik, K., Sweetman, A., Pacyna, J.M. \& Jones, K.C. (2007). Towards a global historical emission inventory for selected PCB congeners - A mass balance approach-3. An update. Sci Total Environ, 377, 296-307.

12. 
566

567

568

569

570

571

572

573

574

575

576

577

578

579

580

581

582

583

584

585

586

587

588

589

590

591

592

593

594

595

Brown, D.W., McCain, B.B., Horness, B.H., Sloan, C.A., Tilbury, K.L., Pierce, S.M. et al. (1998). Status, correlations and temporal trends of chemical contaminants in fish and sediment from selected sites on the Pacific coast of the USA. Mar Pollut Bull, 37, 67-85.

13.

Burnett, R. (1971). DDT residues - Distribution of concentrations in Emerita analoga (stimpson) along coastal California. Science, 174, 606-\&.

14.

Burreau, S., Zebuhr, Y., Broman, D. \& Ishaq, R. (2006). Biomagnification of PBDEs and PCBs in food webs from the Baltic Sea and the northern Atlantic ocean. Sci Total Environ, 366, 659-672.

15.

de Wit, C.A., Herzke, D. \& Vorkamp, K. (2010). Brominated flame retardants in the Arctic environment trends and new candidates. Sci Total Environ, 408, 2885-2918.

16.

Domingo, J.L. (2012). Polybrominated diphenyl ethers in food and human dietary exposure: A review of the recent scientific literature. Food Chem Toxicol, 50, 238-249.

17.

Domingo, J.L. \& Bocio, A. (2007). Levels of PCDD/PCDFs and PCBs in edible marine species and human intake: A literature review. Environment International, 33, 397-405.

18.

Efron, B. \& Tibshirani, R.J. (1994). An introduction to the bootstrap. CRC press.

19.

EPA (2000). Guidance for assessing chemical contaminant data for Use in fish advisories: Volume 1: Fish sampling and analysis. (ed. Water, Oo). United States Environmental Protection Agency

20. Washington, D.C.

EPA (2011). EPA Exposure Factors Handbook.

21.

FAO (2014). State of World Fisheries and Aquaculture 2014. Rome, p. 223.

22.

Fisk, A.T., Hobson, K.A. \& Norstrom, R.J. (2001a). Influence of chemical and biological factors on trophic transfer of persistent organic pollutants in the northwater polynya marine food web. Environ Sci Technol, 35, 732-738.

23.

Fisk, A.T., Stern, G.A., Hobson, K.A., Strachan, W.J., Loewen, M.D. \& Norstrom, R.J. (2001b). Persistent organic pollutants (POPs) in a small, herbivorous, Arctic marine zooplankton (Calanus hyperboreus): Trends from April to July and the influence of lipids and trophic transfer. Mar Pollut Bull, 43, 93-101.

24.

Gewurtz, S.B., McGoldrick, D.J., Clark, M.G., Keir, M.J., Malecki, M.M., Gledhill, M. et al. (2011). Spatial trends of Polybrominated diphenyl ethers in Canadian fish and implications for long-term monitoring. Environ Toxicol Chem, 30, 1564-1575.

25.

Gobas, F.A.P.C., Wilcockson, J.B., Russell, R.W. \& Haffner, G.D. (1999). Mechanism of biomagnification in fish under laboratory and field conditions. Environ Sci Technol, 33, 133-141.

26.

Gobeille, A.K., Morland, K.B., Bopp, R.F., Godbold, J.H. \& Landrigan, P.J. (2006). Body burdens of mercury in lower Hudson River area anglers. Environ Res, 101, 205-212.

27. 
596

597

598

599

600

601

602

603

604

605

606

607

608

609

610

611

612

613

614

615

616

617

618

619

620

621

622

623

624

625

626

627

628

629

630

631

632

633

634

635

636

637

638

639

640

641

642
Greenfield, B.K. \& Allen, R.M. (2013). Polychlorinated biphenyl spatial patterns in San Francisco Bay forage fish. Chemosphere, 90, 1693-1703.

28.

Hammerschmidt, C.R. \& Fitzgerald, W.F. (2006). Bioaccumulation and trophic transfer of methylmercury in Long Island Sound. Archives of Environmental Contamination and Toxicology, 51, 416-424.

29.

Hites, R.A. (2004). Polybrominated diphenyl ethers in the environment and in people: A meta-analysis of concentrations. Environ Sci Technol, 38, 945-956.

30.

Hoekstra, P.F., O'Hara, T.M., Fisk, A.T., Borga, K., Solomon, K.R. \& Muir, D.C.G. (2003). Trophic transfer of persistent orgranochlorine contaminants (OCs) within an Arctic marine food web from the southern Beaufort-Chukchi Seas. Environ. Pollut., 124, 509-522.

31.

Hozo, S.P., Djulbegovic, B. \& Hozo, I. (2005). Estimating the mean and variance from the median, range, and the size of a sample. BMC medical research methodology, 5, 13.

32.

Ikemoto, T., Tu, N.P.C., Watanabe, M.X., Okuda, N., Omori, K., Tanabe, S. et al. (2008). Analysis of biomagnification of persistent organic pollutants in the aquatic food web of the Mekong Delta, South Vietnam using stable carbon and nitrogen isotopes. Chemosphere, 72, 104-114.

33.

Ikonomou, M.G., Teas, H.J., Gerlach, R., Higgs, D. \& Addison, R.F. (2011). Residues of PBDEs in northeastern Pacific marine fish: Evidence for spatial and temporal trends. Environ Toxicol Chem, 30, 1261-1271.

34.

Jensen, S., Johnels, A.G., Olsson, M. \& Otterlin.G (1969). DDT and PCB in marine animals from Swedish waters. Nature, 224, 247-\&.

35.

Jones, K.C. \& de Voogt, P. (1999). Persistent Organic Pollutants (POPs): state of the science. Environ. Pollut., 209-221.

36.

Kallenborn, R. (2006). Persistent organic pollutants (POPS) as environmental risk factors in remote highaltitude ecosystems. Ecotoxicology and Environmental Safety, 63, 100-107.

37.

Kelly, B.C., Ikonomou, M.G., Blair, J.D., Morin, A.E. \& Gobas, F.A.P.C. (2007). Food web-specific biomagnification of persistent organic pollutants. Science, 317, 236-239.

38.

Law, R.J., Alaee, M., Allchin, C.R., Boon, J.P., Lebeuf, M., Lepom, P. et al. (2003). Levels and trends of polybrominated diphenylethers and other brominated flame retardants in wildlife. Environment International, 29, 757-770.

39.

Litz, J.A., Garrison, L.P., Fieber, L.A., Martinez, A., Contillo, J.P. \& Kucklick, J.R. (2007). Fine-scale spatial variation of persistent organic pollutants in Bottlenose dolphins (Tursiops truncatus) in Biscayne Bay, Florida. Environ Sci Technol, 41, 7222-7228.

40.

Lohmann, R., Breivik, K., Dachs, J. \& Muir, D. (2007). Global fate of POPs: current and future research directions. Environ. Pollut., 150, 150-165.

41. 
643

644

645

646

647

648

649

650

651

652

653

654

655

656

657

658

659

660

661

662

663

664

665

666

667

668

669

670

671

672

673

674

675

676

677

678

679

680

681

682

683

684

685

686

687

688

689

690

Mizukawa, K., Takada, H., Takeuchi, I., Ikemoto, T., Omori, K. \& Tsuchiya, K. (2009). Bioconcentration and biomagnification of polybrominated diphenyl ethers (PBDEs) through lower-trophic-level coastal marine food web. Mar Pollut Bull, 58, 1217-1224.

42.

Murray, J. \& Burt, J. (2001). The Composition of Fish. Torry Research Station Ministry of Technology. 43.

Polak-Juszczak, L. (2009). Temporal trends in the bioaccumulation of trace metals in herring, sprat, and cod from the southern Baltic Sea in the 1994-2003 period. Chemosphere, 76, 1334-1339.

44.

Riget, F., Bignert, A., Braune, B., Stow, J. \& Wilson, S. (2010). Temporal trends of legacy POPs in Arctic biota, an update. Sci Total Environ, 408, 2874-2884.

45.

Schade, G. \& Heinzow, B. (1998). Organochlorine pesticides and polychlorinated biphenyls in human milk of mothers living in Northern Germany: Current extent of contamination, time trend from 1986 to 1997 and factors that influence the levels of contamination. Sci Total Environ, 215, 3139.

46.

Schecter, A., Colacino, J., Haffner, D., Patel, K., Opel, M., Päpke, O. et al. (2010a). Perfluorinated compounds, polychlorinated biphenyls, and organochlorine pesticide contamination in composite food samples from Dallas, Texas, USA. Environmental Health Perspectives, 118, 796802.

47.

Schecter, A., Haffner, D., Colacino, J., Patel, K., Päpke, O., Opel, M. et al. (2010b). Polybrominated diphenyl ethers (PBDEs) and hexabromocyclodecane (HBCD) in composite U.S. food samples. Environmental Health Perspectives, 118, 357-362.

48.

Storelli, M.M., Giacominelli Stuffler, R. \& Marcotrigiano, G.O. (1998). Total mercury in muscle of benthic and pelagic fish from the South Adriatic Sea (Italy). Food Addit Contam, 15, 876-883.

49.

Storelli, M.M. \& Marcotrigiano, G.O. (2000). Fish for human consumption: risk of contamination by mercury. Food Addit Contam, 17, 1007-1011.

50.

Strandberg, B., Strandberg, L., van Bavel, B., Bergqvist, P.A., Broman, D., Falandysz, J. et al. (1998). Concentrations and spatial variations of cyclodienes and other organochlorines in herring and perch from the Baltic Sea. Sci Total Environ, 215, 69-83.

51.

Szlinder-Richert, J., Barska, I., Mazerski, J. \& Usydus, Z. (2008). Organochlorine pesticides in fish from the southern Baltic Sea: Levels, bioaccumulation features and temporal trends during the 1995-2006 period. Mar Pollut Bull, 56, 927-940.

52.

Szlinder-Richert, J., Barska, I., Mazerski, J. \& Usydus, Z. (2009). PCBs in fish from the southern Baltic Sea: Levels, bioaccumulation features, and temporal trends during the period from 1997 to 2006. Mar Pollut Bull, 58, 85-92.

53.

Ueno, D., Watanabe, M., Subramanian, A.L., Tanaka, H., Fillmann, G., Lam, P.K.S. et al. (2005). Global pollution monitoring of polychlorinated dibenzo-p-dioxins (PCDDs), furans (PCDFs) and coplanar polychlorinated biphenyls (coplanar PCBs) using skipjack tuna as bioindicator. Environ. Pollut., 136, 303-313. 
69154.

692 Yogui, G.T. \& Sericano, J.L. (2009). Polybrominated diphenyl ether flame retardants in the US marine 693 environment: A review. Environment International, 35, 655-666.

694 
Figure 1 (on next page)

Distribution of data records.

A data record is defined as a mean pollutant concentration value for a distinct combination of species, sampling year, and sampling location. Size of pie charts reflect number of data records included in analysis for each region, with the color codes defining the class of PBT. The 14 global regions designated in study are NE Pacific, NW Pacific, SE Pacific, SW Pacific, Caribbean Sea, Gulf of Mexico, N Atlantic, S Atlantic, Indian, Mediterranean Sea, Baltic Sea, Red Sea, Arctic, and Southern. 


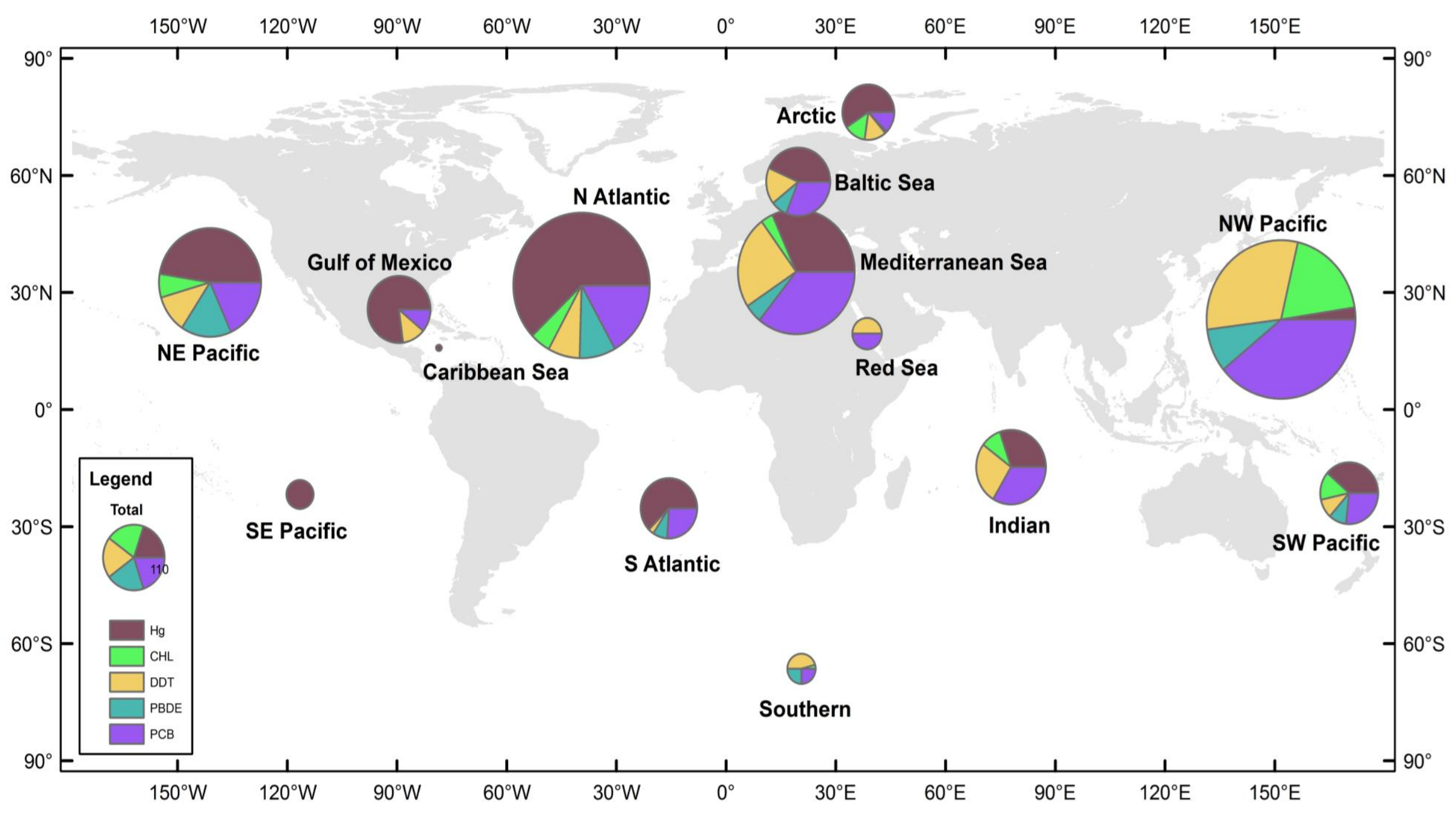




\section{Table $\mathbf{1}$ (on next page)}

Summary of Regional Pollutant Means 


\begin{tabular}{|c|c|c|c|c|c|c|c|c|c|c|}
\hline $\begin{array}{c}\text { Pollutant }^{1} \\
\text { Years }\end{array}$ & \multicolumn{2}{|c|}{$\begin{array}{c}\text { CHL } \\
(1990-2011)\end{array}$} & \multicolumn{2}{|c|}{$\begin{array}{c}\text { DDT } \\
(1990-2012)\end{array}$} & \multicolumn{2}{|c|}{$\begin{array}{c}\mathbf{H g} \\
(1990-2010)\end{array}$} & \multicolumn{2}{|c|}{$\begin{array}{c}\text { PBDE } \\
(1993-2012)\end{array}$} & \multicolumn{2}{|c|}{$\begin{array}{c}\text { РСB } \\
(1990-2012)\end{array}$} \\
\hline Region $^{2}$ & $\begin{array}{c}\text { Mean [95\% } \\
\mathrm{Cl}]\end{array}$ & $N$ & $\begin{array}{c}\text { Mean [95\% } \\
\mathrm{Cl}]\end{array}$ & $N$ & Mean $[95 \% \mathrm{Cl}]$ & $N$ & $\begin{array}{c}\text { Mean [95\% } \\
\mathrm{Cl}] \\
\end{array}$ & $N$ & Mean $[95 \% \mathrm{Cl}]$ & $N$ \\
\hline EPO & $4.0[2.7,5.6]$ & 22 & $\begin{array}{c}23.1[17.1, \\
29.6] \\
42.3[18.0\end{array}$ & 27 & $\begin{array}{c}372.7[282.6 \\
492.4] \\
524.7[304.1\end{array}$ & 146 & $\begin{array}{c}3.7[2.2, \\
5.4] \\
3.1[0.9\end{array}$ & 53 & $\begin{array}{c}4.9[27.4 \\
65.9] \\
37.0[22.0\end{array}$ & 42 \\
\hline WPO & $\begin{array}{c}6.8[4.3,9.7] \\
25.9[11.7,\end{array}$ & 140 & $\begin{array}{c}72.7] \\
9.8[6.2\end{array}$ & 145 & $\begin{array}{c}810.0] \\
430.7[380.8\end{array}$ & 54 & $\begin{array}{c}6.2] \\
1.7[1.2\end{array}$ & 75 & $\begin{array}{c}54.5] \\
249.6[138.8\end{array}$ & 218 \\
\hline $\mathrm{AO}$ & $44.2]$ & 24 & 14.3] & 37 & $\begin{array}{c}485.1] \\
434.2[273.6\end{array}$ & 482 & 2.3] & 54 & $375.3]$ & 108 \\
\hline 10 & $2.3[0.1,8.2]$ & 14 & $3.7[0.9,8.4]$ & 27 & 688.2] & 37 & - & - & $9.3[1.8,19.5]$ & 31 \\
\hline MS & $1.8[0.9,2.9]$ & 12 & $\begin{array}{c}40.2] \\
\end{array}$ & 45 & $\begin{array}{c}418.5[301.1 \\
556.3]\end{array}$ & 76 & $\begin{array}{l}1.6[0.4, \\
3.1]\end{array}$ & 20 & $\begin{array}{c}20.5[18.4, \\
36.5]\end{array}$ & 89 \\
\hline \multicolumn{11}{|c|}{ Trophic Level $^{3}$} \\
\hline $\mathrm{H}$ & $\begin{array}{c}7.1[1.9, \\
17.9] \\
7.6[3.2,\end{array}$ & 13 & $\begin{array}{c}28.5[7.2 \\
107.2] \\
30.5[11.8\end{array}$ & 15 & $\begin{array}{c}462.9[299.6, \\
680.5] \\
492.6[346.4,\end{array}$ & 37 & $\begin{array}{c}2.8[0.6, \\
9.8] \\
2.5[1.0\end{array}$ & 14 & $\begin{array}{c}89.1[20.3, \\
231.0] \\
83.3[33.5,\end{array}$ & 41 \\
\hline$P$ & $\begin{array}{c}13.8] \\
8.7[5.2,\end{array}$ & 42 & $\begin{array}{c}66.4] \\
31.8[16.1,\end{array}$ & 54 & $\begin{array}{c}679.6] \\
409.2[355.6\end{array}$ & 65 & $\begin{array}{c}5.2] \\
2.7[1.6,\end{array}$ & 36 & $\begin{array}{c}159.5] \\
79.1[44.4,\end{array}$ & 99 \\
\hline MP & 12.9] & 130 & 55.5] & 164 & 469.8] & 417 & 4.1] & 133 & 122.8] & 265 \\
\hline TP & $\begin{array}{c}7.6[2.7 \\
16.2] \\
\end{array}$ & 27 & $\begin{array}{c}29.1[11.7 \\
68.7] \\
\end{array}$ & & $\begin{array}{c}429.7[361.5 \\
509.4]\end{array}$ & & $\begin{array}{c}3.3[0.9, \\
8.8] \\
\end{array}$ & & $\begin{array}{c}85.1 \text { [29.3, } \\
166.5] \\
\end{array}$ & 83 \\
\hline \multicolumn{11}{|c|}{ Habitat Type } \\
\hline Benthic & $\begin{array}{c}8.1[4.1, \\
12.1] \\
8.2[13.6\end{array}$ & 61 & $\begin{array}{c}31.4[13.2, \\
57.5] \\
31.0[67.9\end{array}$ & 75 & $\begin{array}{c}416.1[332.8, \\
489.6] \\
419 .\end{array}$ & 186 & $\begin{array}{c}2.8[1.2, \\
4.6] \\
2\end{array}$ & 48 & $\begin{array}{c}83.1[38.8, \\
130.7] \\
80.155 .3\end{array}$ & 142 \\
\hline Demersal & $\begin{array}{l}3.0] \\
83[51\end{array}$ & 121 & 13.0] & 147 & 365.9] & 365 & 1.0] & 122 & $32.5]$ & 238 \\
\hline Pelagic & 16.9] & 30 & 59.6] & 58 & $517.5]$ & 245 & $5.6]$ & 32 & $147.3]$ & 108 \\
\hline
\end{tabular}

all data in $\mathrm{ng} / \mathrm{g}$, wet

weight

2 Regions: EPO-East Pacific Ocean; WPO-West Pacific Ocean; AO-Atlantic Ocean; IO-Indian Ocean; MS- Mediterranean Sea.

${ }^{3}$ Trophic Level: H- Herbivores; P- Primary consumer; MP- Middle consumer; TP- Top consumer. 


\section{Figure 2 (on next page)}

Regional variability of reported PBT concentrations.

Panels a-e show concentration means and 95\% confidence intervals around the mean, per global region (EPO-East Pacific Ocean; WPO-West Pacific Ocean; AO-Atlantic Ocean; IO-Indian Ocean; MS-Mediterranean Sea). Asterisks denote statistically significant differences between regions. Solid line: EPA recreational screening value (logPPB); Dashed line: EPA subsistence screening value (logPPB). Data include records from years 1990-2012. 


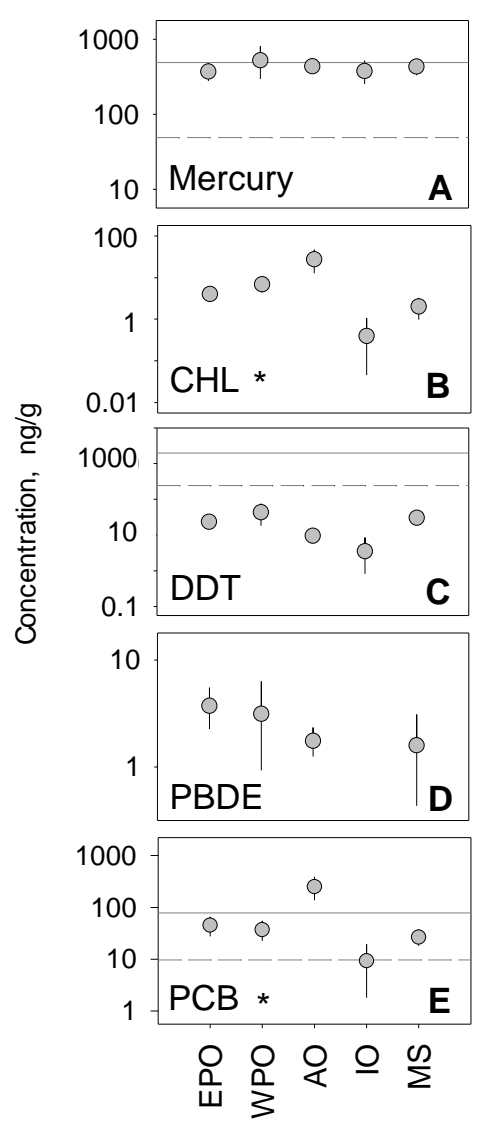




\section{Figure 3 (on next page)}

Regional variability of reported PBT concentrations within each trophic level.

Data presentation and labeling follow that of Figure 2. Data include records from years 19902012. 


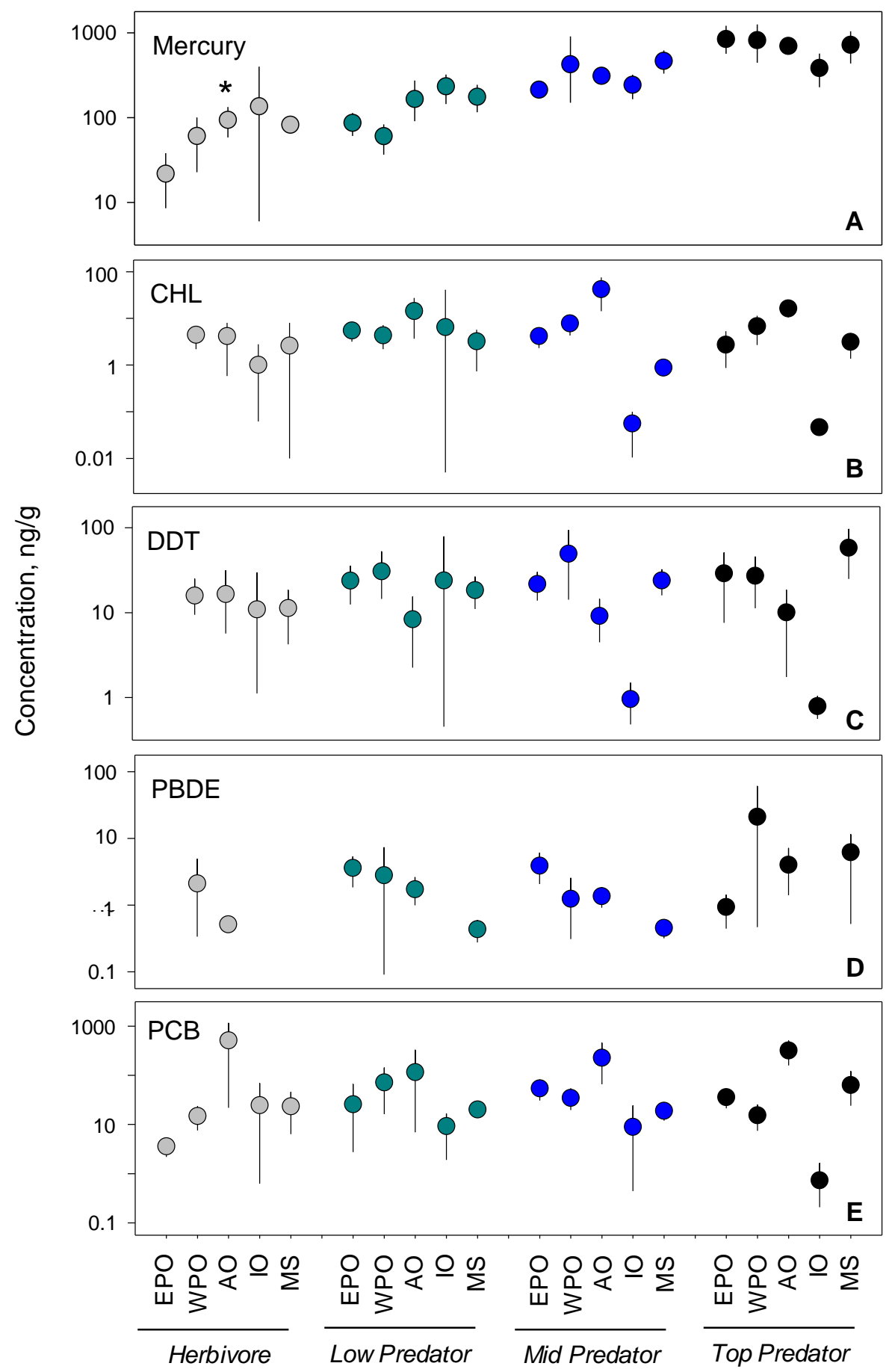


Figure 4 (on next page)

PBT concentrations as a function of trophic level and habitat of samples species.

Panels a-e show concentration means and 95\% confidence intervals around the means per trophic level (H-herbivores; P-low predators; MP-middle predators; TP-top predators). Panels f-j show means and $95 \%$ confidence intervals per habitat. Asterisks denote a statistically significant differences between groups. Data includes records from years 1990-2012. 


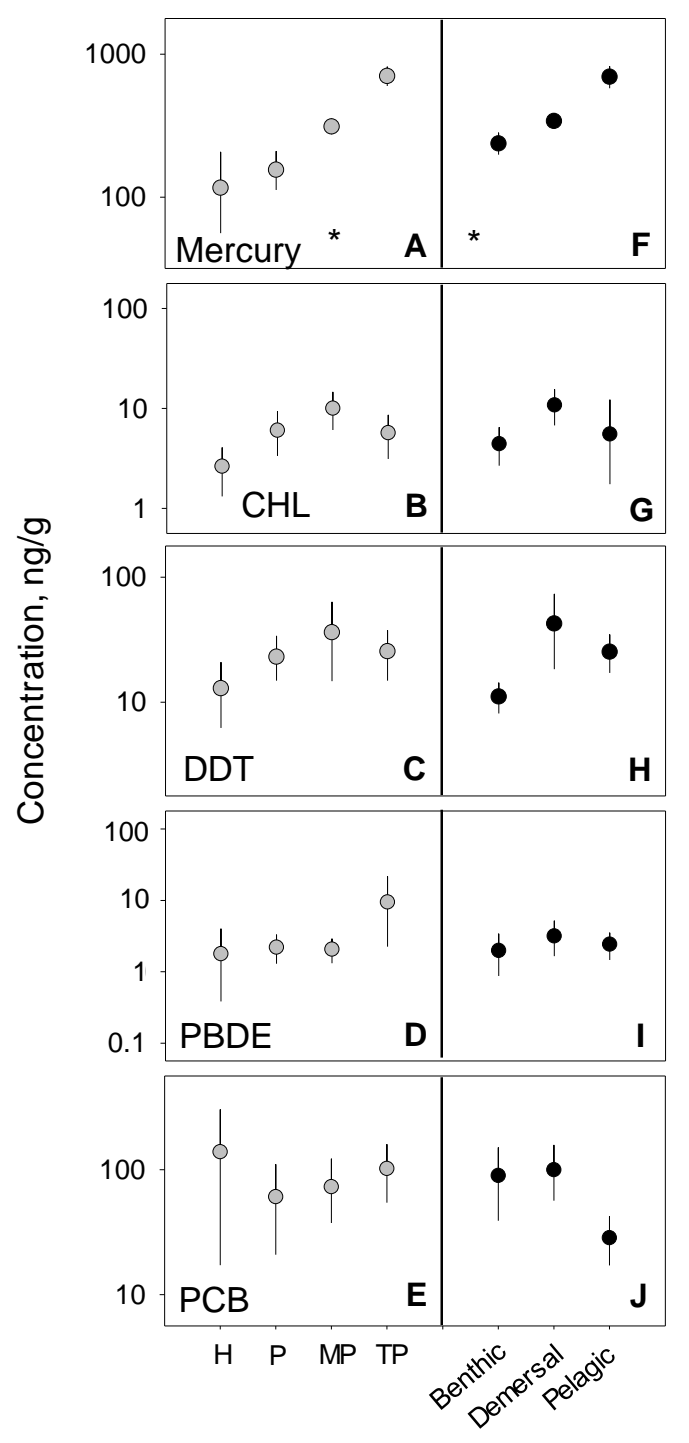


Figure 5 (on next page)

Temporal variability of pollutant concentrations from 1969-2012, inclusive of all trophic guilds and species.

Linear regressions reveal significant, negative trends of log-transformed concentrations through time for each class of PBT. Pollutant concentrations are presented as ng of pollutant per $\mathrm{g}$ wet weight of muscle tissue. 

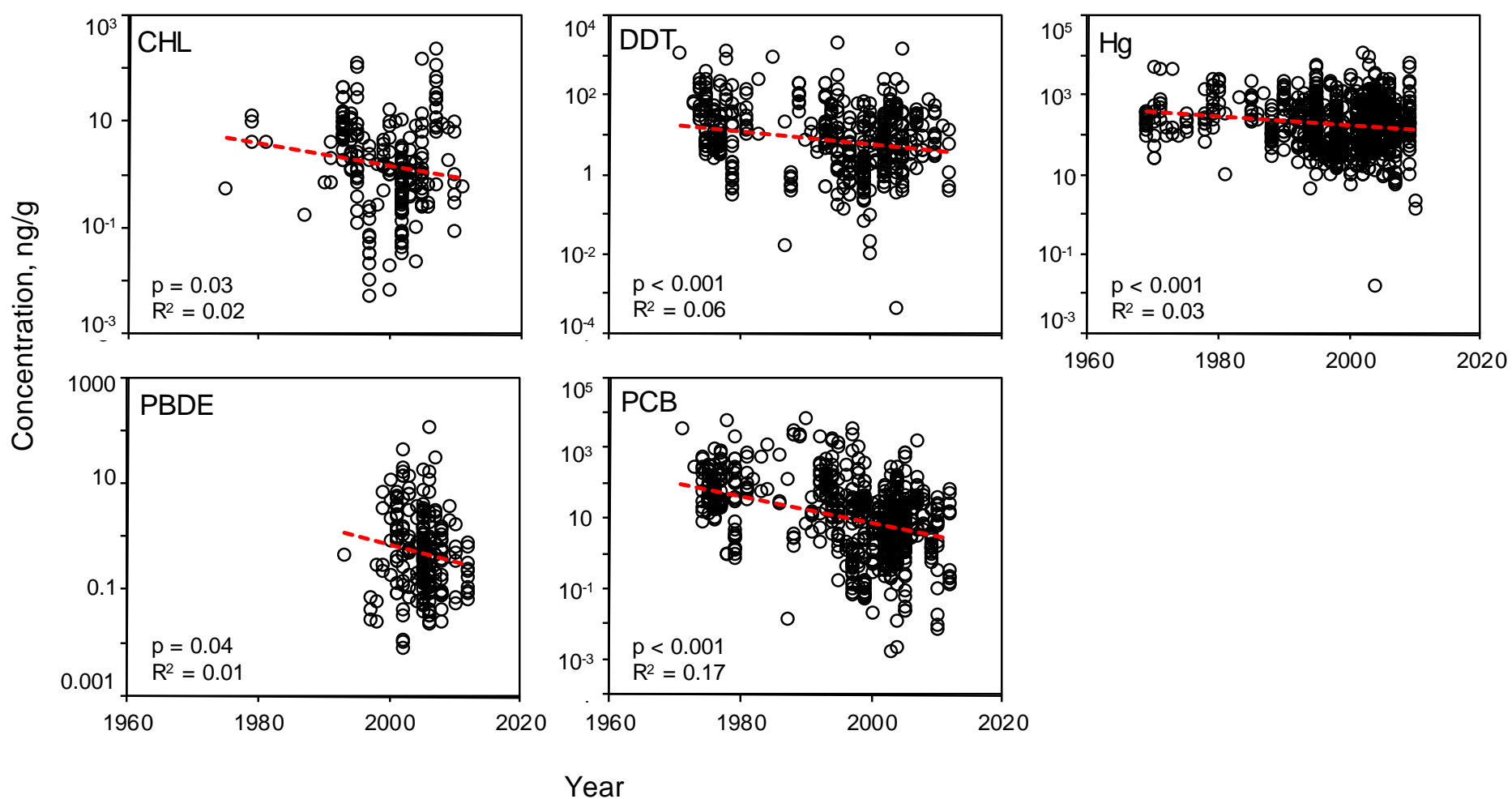